\title{
COMPRESSION AND FLEXURAL PROPERTIES OF FINGER JOINTED MANGO WOOD SECTIONS
}

\author{
V.S Kishan Kumar $\stackrel{\text { I, , C.M Sharma², Sachin Gupta }}{3}$
}

\begin{abstract}
In this paper, an attempt was made to assess the effectiveness of finger jointing in utilising mango wood sections for various end uses like furniture. The study was based on the estimation of Modulus of elasticity and Modulus of rupture under static bending and Maximum Crushing Stress and Modulus of elasticity under compression parallel to grain of finger jointed sections and comparing them with the values measured for clear wood sections from the same lot. For joining the sections, the Poly Vinyl Acetate and Urea Formaldehyde adhesives were used. It was found that the Modulus of elasticity of the sections joined by either adhesive showed significantly better values than that of unjointed clear wood sections. The Modulus of rupture values of sections joined with Urea Formaldehyde were similar to those of unjointed clear wood sections. However, sections jointed with Poly Vinyl Acetate adhesive exhibited lower Modulus of rupture. Under compression, the parameters of the jointed sections joined with either adhesive were either similar or better than those of the unjointed clear wood sections. The study demonstrates the utility of finger jointing of mango wood sections for furniture parts especially with the Urea Formaldehyde adhesive.
\end{abstract}

Keywords: Bending, compression, finger joint, mango wood, poly vinyl acetate, urea-formaldehyde.

\section{INTRODUCTION}

End jointing of lumber to permit the use of single-piece construction has posed a challenge to wood product manufacturers. When the vessels of wood come together in joint, it reduces the strength of the joint. Scarf joints, wherein the adhesive bond is nearly parallel to the grain of the wood alleviated this problem to some extent. Around 1950s, further modifications by different wood researchers resulted in the development of finger joints. A finger joint is roughly considered as two scarf joints separated by a thin butt joint. In general, apart from the glueability of the wood used, the parameters of the finger profile and the adhesive used play important roles in providing strength to the joint. High end manufactures achieve stronger joints by using expensive and high-adhesion glues. But for the small scale furniture manufacturer of any Nation, the feasibility probably ends with the less costly ones especially when the target is the domestic market.

Most individual sections of everyday furniture usually are required to withstand bending and compression stresses. The horizontal members of the chair, the desk or table and the partitions inside a bookshelf are everyday examples which are under a bending stress. The legs of chairs and tables, on the other hand, are under compression stresses. Irrespective of the efficiency of a jointed section with reference to a corresponding clear wood section, it usually is the individual bending and compression load bearing capacities that actually matter in putting the jointed sections into use.

\footnotetext{
Forest Products Division Dehradun 248 006, Uttarakhand, India

${ }^{2}$ Forest Research Institute Dehradun 248 006, Uttarakhand, India

${ }^{3}$ New Forest P.O Dehradun 248 006, Uttarakhand, India

^Corresponding author : krishna@icfre.org

Received: 27.11.2013 Accepted: 26.04. 2014
} 
Wood of Mangifera indica (mango) finds favour with the handicraft industries of India including export markets. Its basic mechanical properties from trees of different Indian locations have been reported by a few authors (Rajput et al. 1996, Shukla and Rajput 1997, Jain et al. 2000). Though not highly durable, it is easily treatable with preservatives. The wood of Mangifera indica has specific gravities around 0,5 and Modulus of Rupture around 56,9-27,6 MPa (Rajput et al. 1996, Jain et al. 2000). The small and medium scale furniture industry usually resorts to less-expensive adhesives for its joinery work.

In literature, strength evaluation of finger jointed sections has been mainly found to be concentrated on temperate species (Fisette and Rice 1988, Samson 1985). As far as hardwoods are concerned, there are some reports from Ghana (Ayarkwa et al. 2000). A recent report from India tries to explain the measured flexural parameters of Eucalyptus in terms of the joint areas (Kumar et al. 2013).

This paper reports the results of a study on the static bending and compression parallel to grain parameters was conducted on finger jointed sections of mango wood joined using Poly Vinyl Acetate (PVA) and Urea Formaldehyde (UF) adhesives.

\section{MATERIALS AND METHODS}

Sample sections were cut from kiln-seasoned (upto 10-12\%) planks of mango wood using a circular saw. Adequately long sections for jointing purposes were cut from the planks for both bending and compression measurements. The sections were selected from visually inspected defect free portions. Approximately 51 $\mathrm{mm}$ thick planks were used for making the samples. Separate clear wood samples were cut from the planks for using as controls. The number of samples for the measurements ranged from eight to twenty depending on the availability of wood material. The sample sizes were kept as of roughly $50 \times 50 \mathrm{~mm}^{2}$ cross section with $750 \mathrm{~mm}$ length for bending measurements and $200 \mathrm{~mm}$ length for compression measurements.

Fingers of $15 \mathrm{~mm}$ length, $5 \mathrm{~mm}$ pitch, $1 \mathrm{~mm}$ tip thickness were profiled using a standard commercial finger shaping machine. For joining the fingers, one of the adhesives used was a commercial PVA. The UF adhesive was prepared from a commercial grade UF resin powder by mixing it with $2 \%$ of ammonium chloride $\left(\mathrm{NH}_{4} \mathrm{Cl}\right)$ hardener and making an aqueous solution with $57,6 \%$ solid content. A brush was used to apply the adhesives to all fingers. Immediately after adhesive application, the sections were mated and pressed on a pneumatic pressing vice at a constant end - pressure of about 5,9 MPa. The jointed sections contained one finger joint in each sample and were made in such a way that the joint occupied the central position of the section. The jointed samples were cured at room temperature for at least 48 hours. Before performing the bending and compression measurements, the samples were given a light planing to remove any adhesive ooze outs.

The static bending measurements on the clear and jointed samples were carried out on a Universal testing machine. The broad directions set down in IS:1708 (1986) were adopted in the measurements. The span for the bending measurements was kept at $700 \mathrm{~mm}$. The load was applied continuously such that the movable head of the testing machine moved at $2,5 \mathrm{~mm}$ per minute. The readings of deflections corresponding to progressively applied loads were recorded. This process was continued until the joints failed in the case of jointed samples or the clear wood samples broke and the loads at which the breaking took place also were recorded for each sample. Figure 1 shows the loading setup used in bending measurements.

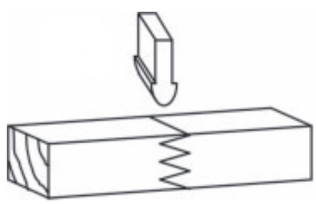

Figure 1. The loading setup in bending measurement of finger jointed sections. 
For compression measurements, continuously increasing load was applied axially on the end surface of the specimen such that the movable head of the testing machine moved at a constant rate at $0,6 \mathrm{~mm} / \mathrm{min}$. The effective length for compression measurement was kept as $150 \mathrm{~mm}$. This procedure was continued till the maximum load was observed. Deflections under compression were recorded at suitable load intervals.

The load deflection graphs were then plotted using spreadsheet. The loads in $\mathrm{N}$ and deflections in $\mathrm{mm}$ were plotted on the ordinate and abscissa respectively. From the graph, the load and deflection at the limit of proportionality were determined as per IS1708 (1986).

For this, the line of proportionality was drawn using the plotted points along the curve so as it passed through most of the initial points. If this line does not pass through the origin, a parallel line was drawn through the origin. The load (P) and deflection (D) corresponding to the limit of proportionality was read from the line passing through the origin.

The Modulus of Rupture (MOR) and Modulus of Elasticity (MOE) were calculated for the bending measurements using the formulae below:

$$
\begin{aligned}
& M O R=\frac{3 P^{\prime} l}{2 b h^{2}}(\mathrm{MPa}) \\
& M O E=\frac{P l^{3}}{4 D b h^{3}}(\mathrm{MPa})
\end{aligned}
$$

where

$\mathrm{P}=$ Load at limit of proportionality $(\mathrm{N})$

$\mathrm{P}^{\prime}=$ Maximum load $(\mathrm{N})$ at which the sample/joint failed

$1=$ Span of sample $(\mathrm{mm})$

$\mathrm{b}=$ Breadth of sample $(\mathrm{mm})$

$\mathrm{h}=$ Height (thickness) of sample $(\mathrm{mm})$

$\mathrm{D}=$ Deflection $(\mathrm{mm})$ at limit of proportionality

In the compression measurements, the Maximum Crushing Stress (MCS) and Modulus of Elasticity (MOE) were calculated for each sample with the formulae given below:

$$
\begin{aligned}
& M C S=\frac{P^{\prime}}{A}(\mathrm{MPa}) \\
& M O E=\frac{P l}{A D}(\mathrm{MPa})
\end{aligned}
$$

where

$\mathrm{P}$ - Load at elastic limit in $\mathrm{N}$

P'- Maximum crushing load in $\mathrm{N}$

A- Cross-sectional area in $\mathrm{mm}^{2}$

1 - Effective length in $\mathrm{mm}$

D - Deflection at limit of proportionality in $\mathrm{mm}$

The statistical comparisons were carried out using the SPSS package. 


\section{RESULTS AND DISCUSSION}

Figures 2 and 3 show typical load-deflection plots of unjointed and sectiones finger jointed with UF and PVA adhesives studied here under static bending (Figure 2) and compression parallel to grain (Figure 3).

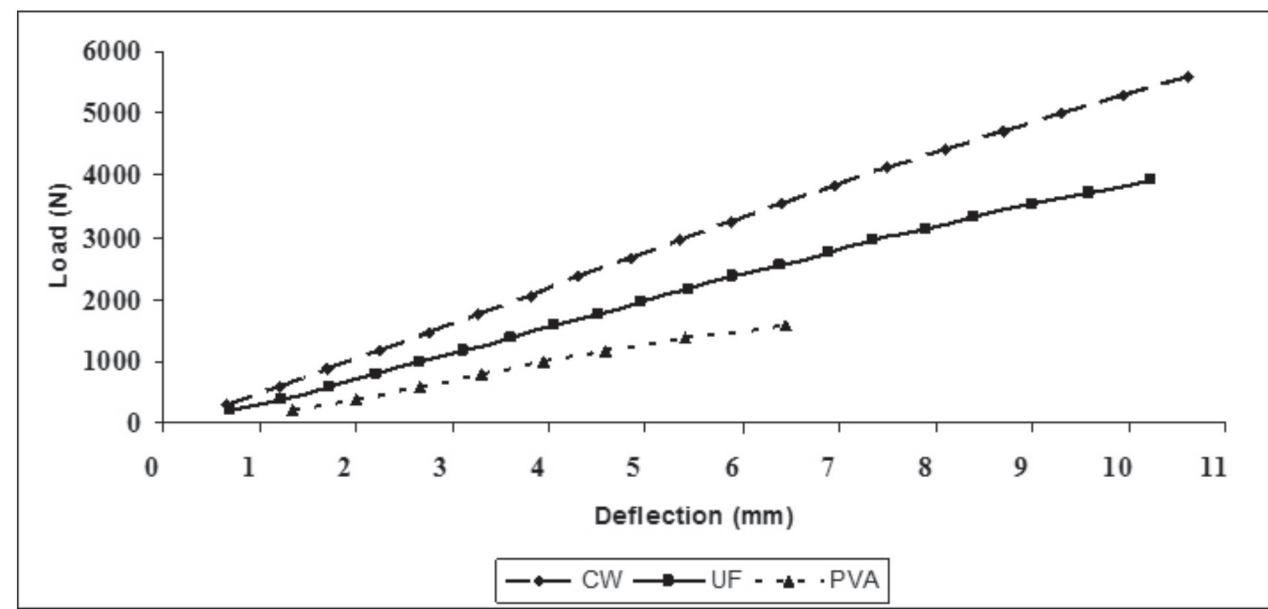

Figure 2. Typical load-deflection graphs under bending.

Note: CW refers to unjointed clear wood samples

UF and PVA refers to samples joined with UF and PVA adhesives respectively.

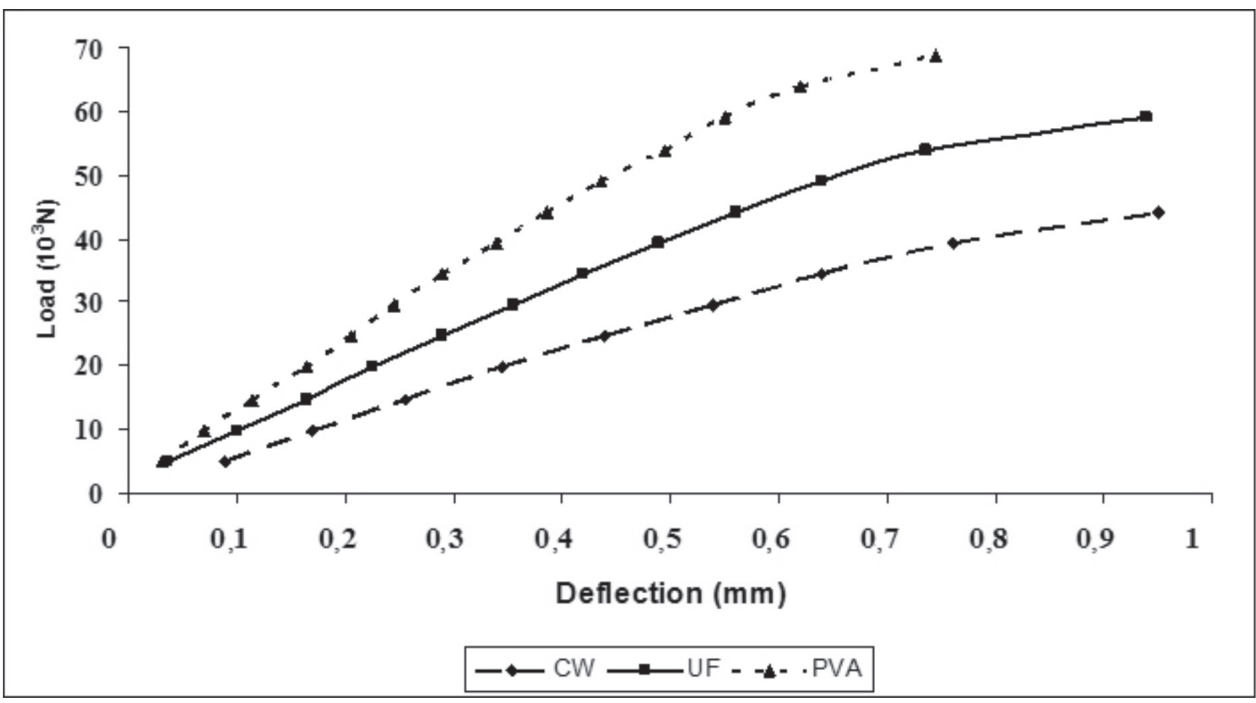

Figure 3. Typical load deflection graphs under compression parallel to grain.

Note: CW refers to unjointed clear wood samples

UF and PVA refers to samples joined with UF and PVA adhesives respectively.

A finger-jointed section will be acceptable for any usage if it has similar, better or the required strength values for a particular utility compared to a similar solid wood section. The data obtained from the present study on the static bending measurements performed on jointed and unjointed clear wood (CW) samples are given in Table 1. The efficiencies of the jointed samples with reference to the values of the CW samples (represented as percentages) are also given for comparison. 
Table 1. Means of Static bending parameters and the efficiencies of jointed samples.

\begin{tabular}{|c|c|c|c|c|c|c|}
\hline \multicolumn{2}{|c|}{ Bending Parameter } & $\mathbf{C W}$ & UF & Eff (\%) & PVA & Eff (\%) \\
\hline \multicolumn{2}{|c|}{ No. of samples $\longrightarrow$} & 10 & 10 & & 10 & \\
\hline \multirow{3}{*}{$\begin{array}{l}\text { MOR } \\
\text { (MPa) }\end{array}$} & Mean & 29,1 & 30,1 & \multirow{3}{*}{103,4} & 14,9 & \multirow{3}{*}{51,2} \\
\hline & SD & 9 & 4,1 & & 3,6 & \\
\hline & CV (\%) & 31,1 & 13,7 & & 24,5 & \\
\hline \multirow{3}{*}{$\begin{array}{l}\text { MOE } \\
\text { (MPa) }\end{array}$} & Mean & 4323 & 5577 & \multirow{3}{*}{129} & 4931 & \multirow{3}{*}{114,1} \\
\hline & SD & 652 & 395 & & 574 & \\
\hline & CV $(\%)$ & 15,1 & 7,1 & & 11,6 & \\
\hline
\end{tabular}

Note: $\quad$ CW refers to unjointed clear wood samples

UF and PVA refers to samples joined with UF and PVA adhesives respectively

Eff $(\%)$ refers to the \% Efficiency of the finger-jointed samples with respect to the unjointed CW samples.

The results obtained from the compression parallel to grain measurements are given in Table 2. Here also, the efficiencies of the jointed samples with reference to the values of the $\mathrm{CW}$ samples (represented as percentages) are given for comparison.

Table 2. Means of Compression parallel to grain parameters and the efficiencies of jointed samples.

\begin{tabular}{|c|c|c|c|c|c|c|}
\hline \multicolumn{2}{|c|}{ Bending Parameter } & $\mathrm{CW}$ & $\mathbf{U F}$ & Eff $(\%)$ & PVA & Eff $(\%)$ \\
\hline \multicolumn{2}{|c|}{ No. of samples $\longrightarrow$} & 8 & 20 & & 14 & \\
\hline \multirow{3}{*}{$\begin{array}{l}\text { MCS } \\
\text { (MPa) }\end{array}$} & Mean & 22,7 & 26.7 & \multirow{3}{*}{117.6} & 22,6 & \multirow{3}{*}{99,6} \\
\hline & SD & 3,2 & 3.3 & & 4,1 & \\
\hline & CV (\%) & 14,2 & 12.2 & & 18,1 & \\
\hline \multirow{3}{*}{$\begin{array}{l}\text { MOE } \\
\text { (MPa) }\end{array}$} & Mean & 4106 & 5185 & \multirow{3}{*}{126.3} & 5319 & \multirow{3}{*}{129,5} \\
\hline & SD & 1350 & 824 & & 1084 & \\
\hline & CV (\%) & 32,9 & 15,9 & & 20,4 & \\
\hline
\end{tabular}

Note: $\quad$ CW refers to unjointed clear wood samples

UF and PVA refers to samples joined with UF and PVA adhesives respectively

Eff (\%) refers to the \% Efficiency of the finger-jointed samples with respect to the unjointed CW samples.

Table 1 indicates that the UF adhesive is far superior to PVA in providing bending strength to the finger jointed sections. UF adhesive has resulted in double the MOR efficiency compared to samples joined with PVA adhesive.

To understand the effect of the adhesives used, the data on the MOR and MOE (unjointed, joined with PVA and joined with UF) were analysed using SPSS. The results of the one-way ANOVA carried out at 95 $\%$ Confidence Interval are presented in Table 3. 
Table 3. Results of ANOVA on the bending parameters of the specimens.

\begin{tabular}{|c|l|c|c|c|c|}
\hline Parameter & \multicolumn{1}{|c|}{ Source } & df & Mean square & F & Significance \\
\hline \multirow{2}{*}{ MOR } & Between Adhesives & 2 & 724,9 & 19.38 & 0,000 \\
\cline { 2 - 5 } & Error & 27 & 37,4 & & \\
\hline \multirow{2}{*}{ MOE } & Between Adhesives & 2 & 3931464 & 12.96 & 0,000 \\
\cline { 2 - 4 } & Error & 27 & 303435 & & \\
\hline
\end{tabular}

Table 3 illustrates that the three types of specimens used show significant differences in their behaviour as far as the bending parameters are concerned. To understand their actual pair wise differences, Duncan's subsets were formed for all the three types of specimens. These are given in Table 4.

Table 4. The subsets of bending parameters formed for the jointed and clear wood samples.

\begin{tabular}{|l|c|c|c|c|c|c|}
\hline Adhesive & \multirow{2}{*}{$\begin{array}{l}\text { Number } \\
\text { uf samples }\end{array}$} & \multicolumn{2}{|c|}{ MOR (MPa) Subsets } & \multicolumn{3}{|c|}{ MOE (MPa) Subsets } \\
\cline { 3 - 7 } & & $\mathbf{1}$ & $\mathbf{2}$ & $\mathbf{1}$ & $\mathbf{2}$ & $\mathbf{3}$ \\
\hline Clear Wood & 10 & & 29,1 & 4323 & & \\
UF & 10 & & 30,1 & & & 5577 \\
PVA & 10 & 14,9 & & & 4931 & \\
Sig. & & 1,000 & 0,712 & 1,000 & 1,000 & 1,000 \\
\hline
\end{tabular}

Table 4 reveals that the bending strength of PVA jointed samples is significantly low. On the other hand, that of UF jointed samples is similar to that of unjointed clear wood. The very same pattern was reported for mango with the same adhesives but with a different finger profile earlier (Kumar et al. 2011). MOR retentions in the range of $75 \%$ has been reported when the fingers were joined using Resorcinol-Formaldehyde in Pinus spp. (Vrazel and Sellers Jr. 2004). Osemeahon et al. (2007) have attributed the utility of a UF based blend with natural rubber as a good joiner to its lesser moisture uptake, melting point, dry time and higher tensile strength. The relatively low retention of bending strength by PVA joined wood sections also have been reported by many workers. Barboutis and Vassiliou (2008) reported MOR efficiencies ranging from $62 \%$ to $76 \%$ when they used four different profiles with very short $(4 \mathrm{~mm})$ to long $(20 \mathrm{~mm})$ fingers in combination with different types of PVA adhesive for Castanea sativa. MOR efficiency of less than $30 \%$ was reported for mango with PVA adhesive but with another finger profile (Kumar et al. 2011). The lower strength of PVA bonds in wood has been attributed to the lower penetration ability of PVA due to the fact that it consists of less mobile and long fibrous molecules (Follrich et al. 2010). Higher performance by UF adhesive over PVA in dowel joints under cyclic bending tests also has been reported (Chou and Lee 2000). In Silver Oak, Rubber wood and Eucalyptus species, the efficiency of UF glued finger jointed sections were reported to be in the $60-65 \%$ of the MOR values of their respective clear sections (Uday et al. 2007) whereas in the present study it is similar to unjointed sections. 
Table 1 reveals that both PVA and UF jointed samples yielded more than $100 \%$ elasticity compared to solid samples. Table 3 indicates that the three types of specimens used show significant differences in their behaviour as far as the elasticity of the specimens are concerned. Table 4 actually groups the MOE values into three different groups with the UF joined samples exhibiting highest MOE followed by the PVA joined samples. With either adhesive, the MOE values are significantly higher than that of unjointed $\mathrm{CW}$ specimens. Higher MOE value for mango wood has already been reported with UF adhesive using another finger profile (Kumar et al. 2011). In the present study, PVA joined samples also exhibit this behaviour.

It is often encountered that finger jointing results in excellent MOE efficiency irrespective of the adhesive used. Vassiliou et al. (2007) reported that MOE of finger jointed samples of Beechwood joined using 10 $\mathrm{mm}$ long fingers and PVA was found unaffected compared to clear samples. The good retention of MOE of finger jointed African hardwood sections using resorcinol-formaldehyde adhesive up to about $83-98 \%$ of the individual clear sections depending on the wood density and with a finger length of $18 \mathrm{~mm}$ also has been reported (Ayarkwa et al. 2000). The study had suggested that lower density hardwoods could produce highly efficient finger joints.

The present study indicates that use of PVA for joining mango wood sections could reduce the bending strength whereas use of UF will result in similar strengths as that of solid sections. On the other hand, the elasticity shows significant improvement with both glues over that of unjointed solid sections. The rupture and elastic properties are reported to be more a property of the wood rather than the adhesive bond (Frihart 2005). The scarf portions of the joint help in minimising wood material discontinuities (River 2003). This is expected to help the mechanical properties of the jointed sections to be not dependent on the adhesive used to very great extents. However, with finger joints, this has been observed usually with MOE rather than with MOR when tested under flexure. In the case of Eucalyptus benthamii also, similar MOE for two different (PVA and polyurethane-based) adhesives has been reported for finger jointed sections (Martins et al. 2013).

Table 2 reveals that both the crushing and elastic behaviour under compression parallel to grain of the jointed sections are higher than that of the clear wood sections. To understand the differences, the actual values were analysed through one way ANOVA and the results are shown in Table 5.

Table 5. Results of ANOVA on the compression parameters of the specimens.

\begin{tabular}{|c|l|c|c|c|c|}
\hline Parameter & Source & df & Mean square & F & Significance \\
\hline \multirow{2}{*}{ MCS } & Between Adhesives & 2 & 89,2 & 7,14 & 0,002 \\
\cline { 2 - 5 } & Error & 39 & 12,5 & & \\
\hline \multirow{2}{*}{ MOE } & Between Adhesives & 2 & 4242552 & 4,04 & 0,025 \\
\cline { 2 - 4 } & Error & 39 & 1049989 & & \\
\hline
\end{tabular}

Table 5 shows that the maximum crushing stresses and MOE under compression of the control and sections joined with the two adhesives are significantly different. To understand their relative differences, Duncan's subsets were formed with SPSS. These subsets are given in Table 6. 
Table 6. The subsets of compression parameters formed for the jointed and clear wood samples.

\begin{tabular}{|l|c|c|c|c|c|}
\hline \multirow{2}{*}{ Adhesive used } & \multirow{2}{*}{$\begin{array}{c}\text { Number of } \\
\text { samples }\end{array}$} & \multicolumn{2}{|c|}{ MCS (MPa) Subsets } & \multicolumn{2}{|c|}{ MOE (MPa) Subsets } \\
\cline { 3 - 6 } & $\mathbf{1}$ & 22,7 & & $\mathbf{1}$ & $\mathbf{2}$ \\
\hline Clear Wood & 8 & 22,6 & & 4106 & \\
PVA & 14 & & 26,7 & & 5319 \\
UF & 20 & & 1,000 & 1,000 & 0,749 \\
Sig. & & 0,943 & &
\end{tabular}

Table 6 illustrates the excellent compression properties of mango wood joined with either of the adhesives. While PVA yielded crushing stress similar to that of unjointed CW sections, the UF glue result in significant improvement in crushing stress. A high retention of strength in compression parallel to grain after finger jointing is often reported. $2 \times 4 \mathrm{in}^{2}$ sections of Radiata pine with centrally located $1 \frac{1}{16}$ inch long fingers gave $90 \%$ strength in compression parallel to grain compared to clear wood (Stanger 1965). In Pinus wallichiana, efficiencies in the range of $88 \%$ to $105 \%$ have been reported with UF adhesive (Pruthi et al. 1985).

In the case of MOE, the efficiencies obtained with the two adhesives in the present study are in excess of $100 \%$. Table 6 shows that both the adhesives result significantly higher elasticities after finger jointing with the profile used in the study. The fact that MOE under compression give high efficiencies is also often encountered. In the case of Radiata pine, the modulus of elasticity did not differ greatly from clear material (Stanger 1965). The efficiencies of MOE reported for $P$. wallichiana were in the $99 \%$ to $110 \%$ range (Pruthi et al. 1985).

Thus, it can be seen that mango wood behaves similarly or better than its solid counterpart under compression parallel to grain when joined with PVA or UF adhesives.

\section{CONCLUSIONS}

The study demonstrates the usefulness of finger jointing where mango wood is used for furniture parts. The bending strength with UF is similar to that of solid sections. The crushing strength with UF adhesive is better than unjointed clear wood sections. The elasticity under both bending and crushing is higher than the clear wood sections with both PVA and UF adhesives. However, the bending strength when PVA is used for joining was found to be only $51 \%$ of that of clear specimens.

\section{ACKNOWLEDGEMENTS}

The authors place on record the help rendered by the staff of Wood Working and Finishing Discipline in making the samples for the study. The help with making the bending and compression measurements by the staff of Timber Mechanics Discipline is highly appreciated. The encouragement by Director, FRI during the study is gratefully acknowledged. 


\section{REFERENCES}

Ayarkwa, J. ; Hirashima, Y.; Sasaki, Y. 2000. Effect of finger geometry and end pressure on the flexural properties of finger-jointed tropical African hardwoods. Forest Products Journal 50 (11-12):53-63.

Barboutis, I.; Vassiliou, V. 2008. Bondability of chestnut wood with PVAc adhesives for furniture production. In (Ed. Badura, R. and M. Ihring) Proceeding of papers from International Conference of NABYTOK 2008, 1-10.

Chou, C.; Lee, M. 2000. Study on the bending fatigue strength of dowel joints. Taiwan J. Forest Science 15 (4): 465-472.

Fisette, P.R.; Rice, W.W. 1988. An analysis of structural finger-joints made from two northeastern species. Forest Products Journal 38 (9): 40-44.

Follrich, J.; Vay, O.; Veigel, S.; Muller, U. 2010. Bond strength of end-grain joints and its dependence on surface roughness and adhesive spread. J Wood Sci 56: 429-434.

Frihart, C.R. 2005. Wood adhesion and adhesives. In: Rowell, R.M. (Ed.), Handbook of wood chemistry and wood composites, Boca Raton, Fla. CRC Press, 2005: 215-278.

IS:1708 1986. Methods of testing of small clear specimens of timber, Part 5 Determination of static bending strength, Bureau of Indian Standards, New Delhi. p. 21-26.

Jain, J.D.; Guru, R.D.; Ranjeet Singh 2000. Physical and mechanical properties of Mangifera indica (Mango) and Syzygium spp. (Jamun) from Dehradun. Indian Forester 126 (9): 948-956.

Kumar, Kishan V.S.; Gupta, Sachin.; Kothiyal, Vimal. 2011. Elasticity and rupture of finger jointed mango wood joined with two adhesives. Indian Forester 137 (1): 88-93.

Kumar Kishan, V. S.; Sharma, C.M.; Gupta, S. 2013. Role of finger tip area on flexural strength properties of finger-jointed sections. International Wood Products Journal 4 (2): 101-106.

Martins, S.A.; Menezzi, C.H.S.D.; Ferraz, J.M.; de Souza, M.R. 2013. Bonding behaviour of Eucalyptus benthamii wood to manufacture edge glued panels. Maderas. Ciencia y tecnología 15(1): 79-92.

Osemeahon, S.A.; Barminas, J.T.; Aliyu, B.A. 2007. Effect of urea formaldehyde viscosity on some physical properties of a composite from reactive blending of urea formaldehyde with natural rubber. International J. Physical Sciences 2 (9): 242-248.

Pruthi, K.S.; Gulati, A.S.; Bajaj, A.N. 1985. Report on the preliminary research investigations on the strength characteristics of glued finger joints. Timber Development Association (India) 30(1): 3-26.

Rajput, S.S.; Shukla, N.K.; Gupta V.K.; Jain, J.D. 1996. Timber Mechanics: Strength, classification and grading of timber. Publication No. ICFRE-38, Indian Council of Forestry Research and Education, Dehradun. p. 189.

River, B.H. 2003. Fracture of adhesive-bonded wood joints. In: Pizzi, A. and Mittal, K.L. (Eds.), Handbook of Adhesive Technology. Marcel Dekker Inc., New York - Basel, chap. 15.

Samson, M. 1985. Potential of finger-jointed lumber for machine stress-rated lumber grades. Forest Products Journal 35 (7-8):20-24. 
Shukla, N.K.; Rajput, S.S. 1997. Physical and mechanical properties of Haryana timber. Van Vigyan 35 (1): 21-29.

Stanger, A.G. 1965. The strength of finger- jointed air-dry radiata pine. Timber Development Association Bulletin 3(1):3-6. Wellington, New Zealand.

Uday, N.D.; Mathews, K.C.; Sujatha, D.; Anand, N. 2007. Enhanced utilization of plantation grown timbers through finger jointing and edge lamination. IPIRTI Technical Report No. 107/2007, pp 6.

Vassiliou, V.; Barboutis, I.; Karastergiou, S. 2007. Effect of PVAc bonding on finger-joint strength of steamed and unsteamed beech wood (Fagus sylvatica). J Appl Polym Sci 103: 1664-1669.

Vrazel, M.; Sellers Jr., T. 2004. The effects of species, adhesive type, and cure temperature on the strength and durability of a structural finger joint. Forest Products Journal 54 (3): 66-75. 